\title{
Cardiovascular risk assessment, cardiovascular disease risk factors, and lung function parameters
}

\author{
Maciej Polak, Agnieszka Doryńska, Krystyna Szafraniec, Andrzej Pająk \\ Chair of Epidemiology and Population Studies Faculty of Health Science, Jagiellonian University, Krakow, Poland
}

\begin{abstract}
Background: Decreased lung function is related to higher cardiovascular disease (CVD) incidence and mortality. However, little is known about the relationship between the risk factors of CVD and pulmonary function.

Aim: The aim of the study was to assess the relationship between the prevalence of cardiovascular risk factors, the total CVD risk, and pulmonary function.

Methods: The analysis included 4104 men and women aged 45 to 69 years, participants of the Polish part of the Health, Alcohol, and Psychosocial factors In Eastern Europe (HAPIEE) Project, who provided valid measurements of forced expiratory volume in one second $\left(\mathrm{FEV}_{1}\right.$ ) and forced vital capacity (FVC) using a Micro-Medical Microplus spirometer. The prevalence of CVD risk factors was defined as follows: hypertension (systolic blood pressure $\geq 140 \mathrm{mmHg}$ or diastolic blood pressure $\geq 90 \mathrm{mmHg}$ or taking hypertension medication), diabetes (glucose $\geq 7.1 \mathrm{mmol} / \mathrm{L}$ or self-reported diabetes), and hypercholesterolaemia (total cholesterol $\geq 5 \mathrm{mmol} / \mathrm{L}$ or low-density lipoprotein-cholesterol $\geq 3 \mathrm{mmol} / \mathrm{L}$ or taking lipid lowering medication). Categories of total CVD risk were defined according to the 2016 European Guidelines on CVD prevention in clinical practice. The analysis of covariance was used to compare the lung function in the CVD risk factors and the total CVD risk categories.

Results: Mean values of $\mathrm{FEV}_{1}$ and $\mathrm{FVC}$, adjusted for age and height, were significantly higher in men than in women (3.02 L; 95\% confidence interval [Cl] 2.96-3.08 L vs. 2.52 L; 95\% Cl 2.45-2.63 L for $\mathrm{FEV}_{1}$ and 3.62 L; 95\% Cl 3.56-3.69 L vs. 3.05 L; 95\% Cl 2.98-3.12 L for FVC). Obesity was significantly associated with FVC in men and women; it was associated with $\mathrm{FEV}_{1}$ only in men. Compared with participants with normal body mass index, obese men and women had $280 \mathrm{~mL}$ and $112 \mathrm{~mL}$ lower mean FVC, respectively. Men without hypertension had almost $100 \mathrm{~mL}$ higher mean FVC than those with hypertension. The difference in FVC in women was approximately $80 \mathrm{~mL}$. Diabetes was associated with lower values of FVC in both sexes and with $\mathrm{FEV}_{1}$ in women. A significant negative trend was observed in the mean FVC and FEV 1 by the considered CVD risk categories. Conclusions: Impaired lung function was associated with higher CVD risk, which could be explained partly by an adverse association between lung function and prevalence of obesity, hypertension, and diabetes.
\end{abstract}

Key words: cardiovascular disease, risk factors, lung function, SCORE

Kardiol Pol 2018; 76, 7: 1055-1063

\section{INTRODUCTION}

In clinical practice, pulmonary function measurement is usually used for identifying persons with airway obstruction or other ventilatory defects. The assessment includes spirometry, which results in outcomes such as forced expiratory volume in one second $\left(\mathrm{FEV}_{1}\right)$ and forced vital capacity (FVC). Persons with results lower than the predicted values, calculated from the measurements of the reference groups (according to age, sex, and height), are considered to have low pulmonary function [1].
Lung function parameters can be used for predicting morbidity and mortality [2]. Besides association with chronic obstructive pulmonary disease (COPD) and lung cancer [2], low pulmonary function was found to be related to cardiovascular disease (CVD) [3], coronary artery disease [2], atrial fibrillation [4], diabetes [5], and other disadvantageous conditions such as obesity [5], hypertension [6], high low-density lipoproteins (LDLs), and low high-density lipoproteins (HDLs) [7]. Pulmonary dysfunction has been found in persons with metabolic syndrome and diabetes [5], asthma [8], and

\section{Address for correspondence:}

Mgr Maciej Polak, Chair of Epidemiology and Population Studies Faculty of Health Science, Jagiellonian University, ul. Grzegórzecka 20, $31-531$ Kraków, Poland, e-mail: maciej.1.polak@uj.edu.pl 
lung disease [9]. Reports of pulmonary function assessment in the general population are not very extensive $[10,11]$. Moreover, the relationship between pulmonary function and CVD risk factors has thus far been assessed for separate risk factors [5-7, 12], while evidence of the relationship between lung function and the combined effect of CVD risk factors, i.e. total CVD risk in the same individuals, is scarce [3, 13]. Therefore, the aim of the present study was to assess the relationship between the prevalence of cardiovascular risk factors, the total CVD risk, and pulmonary function.

\section{METHODS}

The analysis was performed using data from the Polish part of the Health, Alcohol, and Psychosocial factors In Eastern Europe (HAPIEE) Project, which is described in detail elsewhere [14]. A brief summary relevant to the present analysis is given below. The HAPIEE Project involved a random sample of Kraków residents aged between 45 and 69 years at the baseline. Trained nurses interviewed respondents in their homes. Information on age, education, marital status, employment status, health status (history of CVD, asthma, hypertension, diabetes, and hypercholesterolaemia), and health behaviours (smoking and physical activity) was obtained using a standard questionnaire. Then, all participants were invited to the clinic for anthropometric and blood pressure (BP) measurements followed by blood collection for biochemical tests, and subsequent spirometry. Height and weight were measured in the vertical position by using electronic scales with a built-in ruler in participants wearing light indoor clothing and no shoes.

Physical activity measurement was based on the question "How many hours during a typical week do you engage in sports, games, or hiking?" Participants' responses were categorised according to the guidelines of the World Health Organisation. The recommended physical activity was defined as at least $150 \mathrm{~min}$ of moderate-intensity aerobic physical activity throughout the week, and poor if more than 0 min but less than 150 min per week. Furthermore, a participant was defined as an inactive person when the time of physical activity was 0 . The body mass index (BMI) was calculated as weight in kilograms divided by the square of height in metres. In the analysis, we included participants with $\mathrm{BMI} \geq 18.5 \mathrm{~kg} / \mathrm{m}^{2}$. The smoking status was coded as current, former, or never-smoker. Hypertension was defined as systolic BP (SBP) $\geq 140 \mathrm{mmHg}$ and/or diastolic BP (DBP) $\geq 90 \mathrm{mmHg}$, or when the participant was on medication for hypertension. Diabetes was categorised as either self-reported diabetes (defined as self-reported history of diabetes or use of hypoglycaemic medication) or detected diabetes (defined as fasting serum glucose level $\geq 7.0 \mathrm{mmol} / \mathrm{L}$ ). A participant was considered to have hypercholesterolaemia if his/her total cholesterol (TC) level was $\geq 5.0 \mathrm{mmol} / \mathrm{L}$, his/her LDL cholesterol (LDL-C) level was $\geq 3.0 \mathrm{mmol} / \mathrm{L}$, or he $/ \mathrm{she}$ was on lipid-lowering medication.
The 10-year risk of fatal CVD (SCORE risk) was calculated using the algorithm for high-risk countries [15], which included the participants' age, sex, smoking status, TC level, and SBP. SCORE was calculated for participants who did not report a history of diabetes mellitus, myocardial infarction, or stroke at the baseline health assessment, and for individuals who required a complete dataset on CVD risk factors. SCORE was categorised as low or moderate (SCORE $<5 \%$ ), high $(5 \% \leq \operatorname{SCORE}<10 \%)$, and very high (SCORE $\geq 10 \%)$. Based on information about heart attack/acute myocardial infarction, stroke, diabetes, smoking status, prevalence of CVD risk factors, and the SCORE value, the total CVD risk for each participant was estimated according to the European Guidelines on Cardiovascular Disease Prevention in Clinical Practice (version 2016) [16].

\section{Pulmonary function assessment}

Pulmonary function was assessed in a randomly selected part of the studied sample. In the current study, we used two measures: FVC and $\mathrm{FEV}_{1}$, which were measured by a trained technician in accordance with a standardised protocol [17], using a Microplus (Micro-Medical Ltd., Rochester, United Kingdom) spirometer. Subjects performed spirometry in the standing position with a nose clip in place. They were asked to make at least three maximal expiratory manoeuvres. The highest values of FVC and $\mathrm{FEV}_{1}$ were chosen from measurements that met the acceptability criteria of satisfactory and repeatability exhalation [17]. Furthermore, before the spirometric examination, the participants were interviewed on their current health status (any surgery within the three months preceding the examination or the use of an inhaler for asthmatic patients), as well as their current smoking and drinking behaviours.

\section{Statistical analysis}

Descriptive statistics were calculated according to sex as means and standard deviations for pulmonary function parameters and as the prevalence rate for categorical variables. To compare the FVC and $\mathrm{FEV}_{1}$ distributions for classical CVD risk factors and the category of total CVD risk, an analysis of covariance was performed. All analyses were performed separately for men and women. Interactions between age and education level and the considered risk factors were verified; however, because these interactions were not statistically significant, they were not included in the final model. The final model was adjusted for age, height, education level, physical activity (categorical variable), smoking status, smoking frequency (pack-years), and the prevalence of respiratory diseases (yes/no). Moreover, because of the strong association between smoking and lung function, the models were repeated with stratification by smoking status. The $\chi^{2}$ test was used to compare the distribution of CVD risk factors between men and women and between participants who were included 
Table 1. Descriptive statistics of the studied group

\begin{tabular}{|c|c|c|c|}
\hline & Men $(n=2020)$ & Women $(n=2084)$ & $\mathbf{p}$ \\
\hline Age [years] & $57.91 \pm 6.86$ & $57.2 \pm 7.00$ & 0.001 \\
\hline University level of education & $609(30.2 \%)$ & $539(25.9 \%)$ & 0.002 \\
\hline Respiratory disease & $266(13.2 \%)$ & $285(13.7 \%)$ & 0.7 \\
\hline Physical activity: & & & 0.7 \\
\hline Inactive & $523(26.9 \%)$ & $525(26.5 \%)$ & \\
\hline Poor & $236(12.1 \%)$ & $226(11.4 \%)$ & \\
\hline Recommended & $1185(61.0 \%)$ & $1228(62.1 \%)$ & \\
\hline BMI: & & & $<0.001$ \\
\hline Normal & $430(21.6 \%)$ & $542(26.7 \%)$ & \\
\hline Overweight & $1001(49.8 \%)$ & 807 (38.8\%) & \\
\hline Obesity & $575(28.6 \%)$ & $716(34.5 \%)$ & \\
\hline Smoking status: & & & $<0.001$ \\
\hline Current & $666(33.1 \%)$ & $539(25.9 \%)$ & \\
\hline Former & $755(37.5 \%)$ & $419(20.2 \%)$ & \\
\hline Never & $592(29.4 \%)$ & $1121(53.9 \%)$ & \\
\hline Hypertension & $1344(67.1 \%)$ & $1115(53.8 \%)$ & $<0.001$ \\
\hline Diabetes & $337(16.7 \%)$ & $270(13.0 \%)$ & 0.001 \\
\hline Hypercholesterolaemia & $1694(84.2 \%)$ & $1807(87.0 \%)$ & 0.01 \\
\hline SCORE risk category: & & & $<0.001$ \\
\hline Low or moderate & $597(43.7 \%)$ & $1291(86.0 \%)$ & \\
\hline High & $437(32.0 \%)$ & $160(10.7 \%)$ & \\
\hline Very high & $333(24.4 \%)$ & $51(3.4 \%)$ & \\
\hline CVD risk category: & & & $<0.001$ \\
\hline Low or moderate & $576(28.7 \%)$ & $1239(60.0 \%)$ & \\
\hline High & $462(23.1 \%)$ & $216(10.5 \%)$ & \\
\hline Very high & $966(48.2 \%)$ & $611(29.6 \%)$ & \\
\hline
\end{tabular}

Data are shown as mean \pm standard deviation or number (percentage). BMI — body mass index; CVD — cardiovascular disease

in the analysis and those who were excluded. Data were analysed using Statistical Package for the Social Sciences (SPSS) version 22.0 (SPSS Inc., Armonk, NY, USA). All tests were two-tailed, $\mathrm{p}$-value less than 0.05 was considered statistically significant.

\section{RESULTS}

Out of the 4840 participants who performed spirometry, $4104(84.4 \%)$ completed adequate lung function measurement. Those who were unable to complete the measurement were more likely to be smokers (34\% vs. $26 \%$, $p=0.043$ ) and had a higher prevalence of respiratory diseases $(18 \%$ vs. $13 \%, p=0.003)$. No significant difference in sex, age, and prevalence of CVD risk factors between these two groups was observed.

Descriptive statistics of the studied group are presented in Table 1. The mean age was $55.6 \pm 6.92$ years; men were slightly older than women (57.9 years vs. 57.2 years, $\mathrm{p}<0.001)$. The mean $\mathrm{FEV}_{1}$ adjusted for age and height was significantly higher in men than in women $(3.02 \mathrm{~L} ; 95 \%$ confidence interval $[\mathrm{Cl}] 2.96-3.08 \mathrm{~L}$ vs. $2.52 \mathrm{~L} ; 95 \% \mathrm{Cl}$ 2.45-2.63 L). The mean FVC adjusted for age and height was $3.25 \mathrm{~L}(95 \% \mathrm{Cl} 3.22-3.28 \mathrm{~L})$; the difference in the mean FVC between men and women was $0.57 \mathrm{~L}$ and was statistically significant: $3.62 \mathrm{~L}(95 \% \mathrm{Cl} 3.56-3.69 \mathrm{~L})$ and $3.05 \mathrm{~L}(95 \% \mathrm{Cl}$ 2.98-3.12 L), respectively. No differences were observed in the prevalence of respiratory disease and physical activity levels between men and women. The prevalence of CVD risk factors differed between sexes. Men smoked more frequently than women. Furthermore, a greater number of men had hypertension and diabetes than women, while the prevalence of obesity and hypercholesterolaemia was higher in women. The SCORE risk value was calculated for 2889 participants (excluding those with a history of diabetes mellitus, myocardial infarction, and/or stroke). The proportion of participants with a very high risk (SCORE $\geq 10$ ) was approximately seven 
Table 2. Relationship between forced expiratory volume in one second (FEV $)$ and cardiovascular disease (CVD) risk factors and total CVD risk

\begin{tabular}{|c|c|c|c|c|c|c|c|c|}
\hline & \multicolumn{4}{|c|}{ Men } & \multicolumn{4}{|c|}{ Women } \\
\hline & $\mathbf{n}$ & Mean* [CL] & $95 \% \mathrm{Cl}$ & p & $\mathbf{n}$ & Mean* [cL] & $95 \% \mathrm{Cl}$ & $\mathbf{p}$ \\
\hline BMI: & & & & $<0.001$ & & & & 0.06 \\
\hline Normal & 427 & 305.86 & $300.4-311.3$ & & 547 & 218.50 & $214.8-222.2$ & \\
\hline Overweight & 983 & 306.60 & $302.5-310.7$ & & 797 & 219.87 & $216.6-223.4$ & \\
\hline Obesity & 564 & 290.15 & $258.3-295.0$ & & 705 & 215.35 & $212.0-218.7$ & \\
\hline Hypertension: & & & & 0.01 & & & & 0.001 \\
\hline No & 310 & 305.20 & $300.3-310.1$ & & 947 & 219.89 & $216.6-223.2$ & \\
\hline Yes & 1664 & 298.96 & 294.8-303.1 & & 1095 & 214.14 & 210.9-217.4 & \\
\hline Hypercholesterolaemia: & & & & 0.2 & & & & 0.25 \\
\hline No & 274 & 297.49 & 291.1-303.9 & & 267 & 214.79 & $209.8-219.8$ & \\
\hline Yes & 1523 & 301.88 & 297.9-305.8 & & 1781 & 217.62 & $214.7-220.5$ & \\
\hline Diabetes: & & & & 0.1 & & & & 0.03 \\
\hline No & 1646 & 302.16 & $298.2-306.1$ & & 1782 & 217.89 & $215.0-220.7$ & \\
\hline Yes & 330 & 297.05 & 290.9-303.2 & & 263 & 212.40 & $207.3-217.5$ & \\
\hline CVD risk category: & & & & 0.01 & & & & $<0.001$ \\
\hline Low or moderate & 570 & 305.75 & $300.0-311.5$ & & 1230 & 220.57 & $217.4-223.7$ & \\
\hline High & 456 & 303.74 & 298.0-309.4 & & 215 & 215.85 & $210.2-221.5$ & \\
\hline Very high & 947 & 297.32 & 292.7-301.9 & & 598 & 211.48 & $207.7-215.2$ & \\
\hline
\end{tabular}

*Obtained by analysis of covariance, adjusted for age, height, education level, physical activity, smoking status, smoking frequency, and the prevalence of respiratory diseases; $\mathrm{BMI}$ — body mass index; $\mathrm{CL}$ — centilitres; $\mathrm{Cl}$ — confidence interval

times higher in men than in women. The percentage of men in the very high total CVD risk category was approximately $63 \%$ higher than that of women.

Results of the analyses of the relationship between the different CVD risk factors and CVD risk categories and lung function are presented in Tables 2 and 3, respectively. Obesity was significantly associated with FVC in men and in women, but the relationship between obesity and $\mathrm{FEV}_{1}$ was significant only in men. Compared with that of the participants with normal $\mathrm{BMI}$, the FVC of men and women with obesity was $280 \mathrm{~mL}$ and $112 \mathrm{~mL}$ lower, respectively. Both $\mathrm{FEV}_{1}$ and FVC were strongly related to hypertension. Men free of hypertension had $93 \mathrm{~mL}$ higher mean FVC than those with hypertension. The difference in FVC in women was approximately $80 \mathrm{~mL}$. Diabetes was significantly and inversely associated with FVC in both sexes and with $\mathrm{FEV}_{1}$ in women. The adjusted difference in mean FVC in women was approximately $90 \mathrm{~mL}$, and it was $155 \mathrm{~mL}$ in men. Hypercholesterolaemia was not significantly related with $\mathrm{FEV}_{1}$ and $\mathrm{FVC}$. A significant negative trend was observed in the mean FVC and $\mathrm{FEV}_{1}$ in both sexes for the total CVD risk categories. Compared with participants with low or moderate risk, men with a very high CVD risk had a relatively low mean FVC of approximately $180 \mathrm{~mL}$; women had a mean FVC of approximately $110 \mathrm{~mL}$ (Figs. 1, 2).

After stratification by smoking status, the results were similar to those obtained in the pooled analysis. Tables 4 and 5 present the relationship between $\mathrm{FEV}_{1}, \mathrm{FVC}$, and the different CVD risk factors and CVD risk categories in the never-smokers and in the current or former smokers. Lung function was naturally worse in the current and former smokers; however, besides the relationship between $\mathrm{FEV}_{1}$ and hypertension and FVC and a few of the risk factors (BMI, hypertension, diabetes, and CVD risk) in smoking women, other associations that were significant in the pooled analysis remained significant in the never-smokers and in the current or former smokers. Restriction of the group only to the current smokers did not substantially change the results.

\section{DISCUSSION}

In the current study, we observed a relationship between pulmonary function and CVD risk factors such as obesity, hypertension, and diabetes and pulmonary function; however, a relationship between hypercholesterolaemia and pulmonary function was not found. The results obtained in the group of never-smokers showed the same pattern, although it was not significant in the case of hypertension, probably because of the relatively small number of participants and insufficient statistical power. Furthermore, a relationship between both $\mathrm{FEV}_{1}$ and $\mathrm{FVC}$, and CVD risk categories was observed in the study. These results are similar to those obtained by other researchers $[3,5,6]$, although the mean value of spirometric parameters obtained in our study differed slightly from the 
Table 3. Relationship between forced vital capacity (FVC) and cardiovascular disease (CVD) risk factors and total CVD risk

\begin{tabular}{|c|c|c|c|c|c|c|c|c|}
\hline & \multicolumn{4}{|c|}{ Men } & \multicolumn{4}{|c|}{ Women } \\
\hline & $\mathbf{n}$ & Mean* [cL] & $95 \% \mathrm{Cl}$ & p & $\mathbf{n}$ & Mean* [cL] & $95 \% \mathrm{Cl}$ & p \\
\hline BMI: & & & & $<0.001$ & & & & $<0.001$ \\
\hline Normal & 382 & 384.5 & $377.9-391.0$ & & 513 & 273.7 & $269.3-278.1$ & \\
\hline Overweight & 889 & 375.1 & $370.1-380.0$ & & 752 & 269.9 & $266.1-273.7$ & \\
\hline Obesity & 525 & 356.5 & $350.7-362.3$ & & 658 & 262.5 & $258.5-266.4$ & \\
\hline Hypertension: & & & & 0.002 & & & & $<0.001$ \\
\hline No & 578 & 378.0 & $372.0-383.9$ & & 881 & 271.6 & $267.8-275.5$ & \\
\hline Yes & 1214 & 368.7 & $363.8-373.7$ & & 1039 & 264.0 & $260.3-267.8$ & \\
\hline Hypercholesterolaemia: & & & & 0.3 & & & & 0.99 \\
\hline No & 274 & 368.0 & $360.3-375.7$ & & 248 & 267.8 & 261.9-273.7 & \\
\hline Yes & 1523 & 372.1 & $367.4-376.8$ & & 1678 & 267.8 & $264.5-271.2$ & \\
\hline Diabetes: & & & & $<0.001$ & & & & 0.002 \\
\hline No & 1495 & 374.6 & $369.8-379.3$ & & 1679 & 268.9 & $265.5-272.2$ & \\
\hline Yes & 305 & 359.1 & $351.7-366.5$ & & 244 & 259.9 & $253.8-265.9$ & \\
\hline CVD risk category: & & & & $<0.001$ & & & & $<0.001$ \\
\hline Low or moderate & 517 & 382.8 & 375.9-389.7 & & 1161 & 271.4 & $267.8-275.1$ & \\
\hline High & 427 & 371.2 & $364.4-377.9$ & & 195 & 268.4 & $261.6-275.1$ & \\
\hline Very high & 851 & 365.1 & $359.5-370.7$ & & 563 & 260.6 & $256.2-265.0$ & \\
\hline
\end{tabular}

*Obtained by covariance, adjusted for age, height, education level, physical activity, smoking status, smoking frequency, and the prevalence of respiratory diseases. Abbreviations - see Table 2

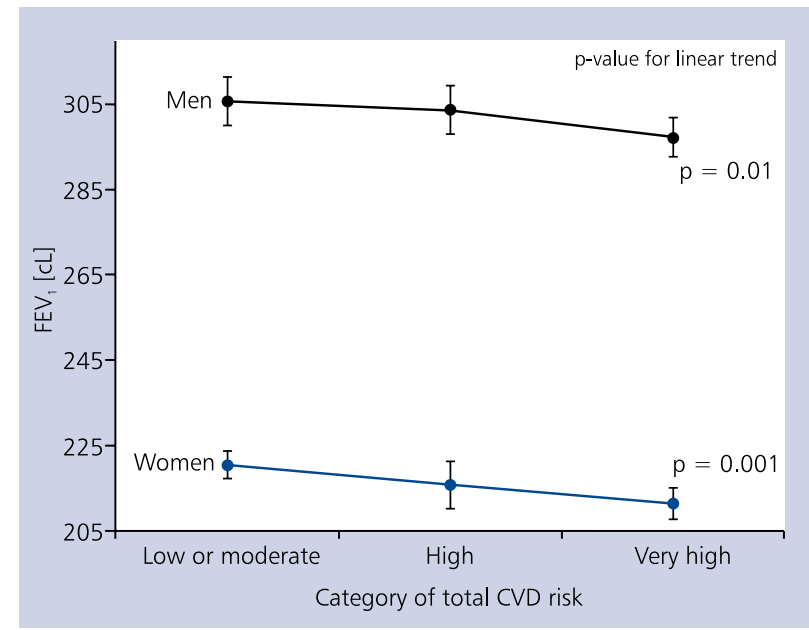

Figure 1. Mean value of forced expiratory volume in one second $\left(\mathrm{FEV}_{1}\right)$ in categories of total cardiovascular disease (CVD) risk by sex

other populations. However, it should be taken into account that direct comparison of FVC and FEV 1 may be difficult due to the different age range of the studied groups. If the comparison is limited to the studies that included participants of similar age, the mean FVC and FEV $_{1}$ obtained in the current

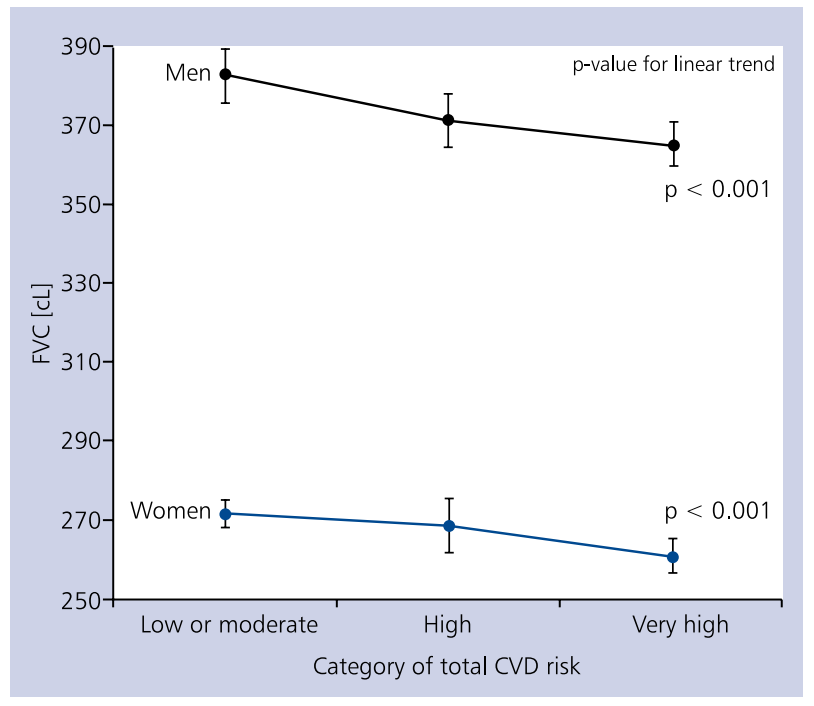

Figure 2. Mean value of forced vital capacity (FVC) in categories of total cardiovascular disease (CVD) risk by sex

study were lower compared to Polish part of the BOLD study (which included populations of Chrzanów and Proszowice) and to the Italian study that involved 8000 participants. It is likely that worse pulmonary function in residents of Kraków 


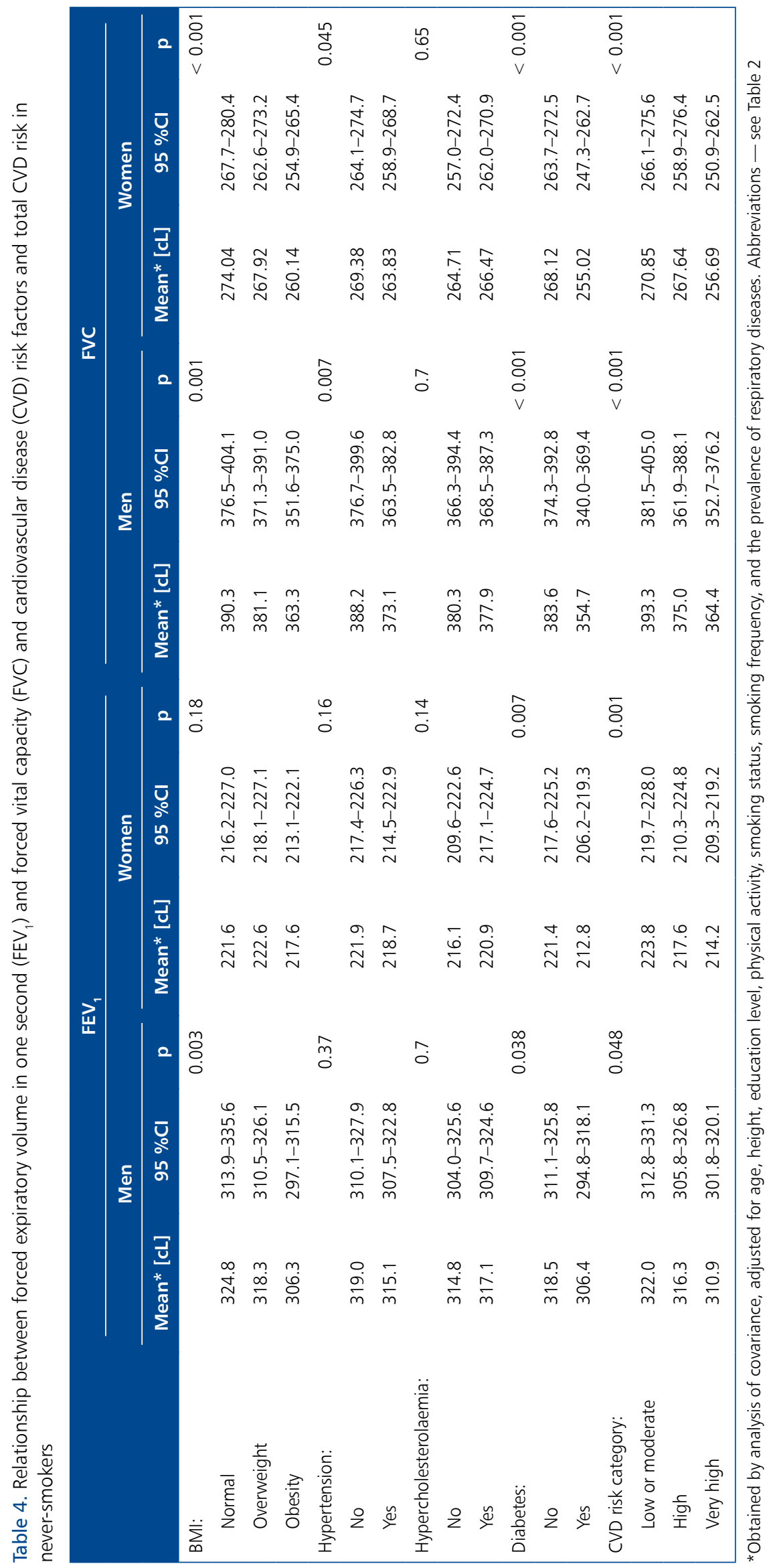




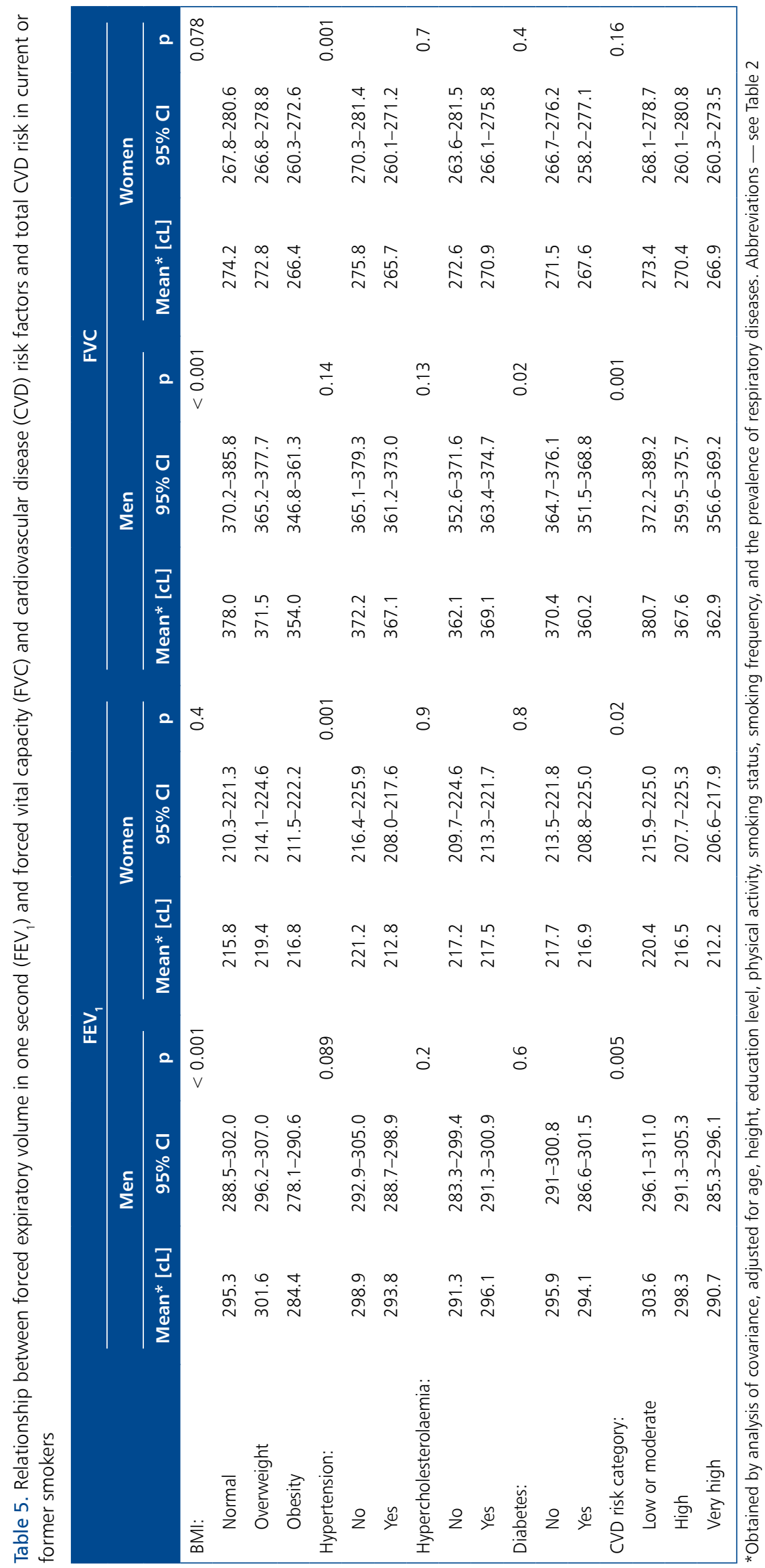


could be explained by air pollution and a higher smoking rate $[12,18]$.

The underlying mechanism of the relationship between pulmonary function and CVD risk factors is unclear, except for smoking, which may affect respiratory functioning and increase the CVD risk. The inflammation process was suggested to be involved in this mechanism. For example, it has been found that metabolic syndrome, which causes inflammation in the lungs, may influence the further occurrence of lung function impairment [19]. It has also been observed that systemic inflammation in participants with airflow obstruction could be associated with an increased risk of cardiac injury [20]. COPD, characterised by disabled lung function, is associated with systemic inflammation, and an increased risk of CVD was observed in patients with COPD. The glycosylation of protein (such as collagen in the lungs and the chest wall) may also play a role in the relationship between diabetes and impaired lung function. Decreased lung function observed among diabetic patients may be explained by collagen accumulation in the lung connective tissue [21]. Respiratory impairment among persons with diabetes might be influenced by increased $\mathrm{BMI}$ and result in fat deposits between the muscles and the ribs, which decrease chest wall compliance and weaken the respiratory muscles [22]. Other researchers have suggested that some processes that may lead to CVD risk factors (such as alterations in arterial functions) may share similar physiopathological pathways as those that result in impaired respiratory function, but the nature of these relationships remains unknown [23].

We may assume that the inverse relationship between lung function and CVD risk categories was a result of the fact that the CVD risk categories were based on several risk factors (diabetes, hypertension, etc.), which were directly related to impaired lung function.

This study has several limitations that need to be considered when interpreting the results. First, the data were collected in a cross-sectional manner, which made the assessment of the direction of the relationship difficult and did not allow us to conclude a cause-effect relationship. There are suggestions in both directions of the relationship between pulmonary function and CVD risk. Poor pulmonary function may influence the further development of CVD risk factors [24]. On the other hand, exposure to CVD risk factors may trigger the further dysfunction of lungs [19]. Second, although we examined a part of the random population sample, this sample consisted of citizens of a large Polish city and was not representative of the entire Polish population. Moreover, the examinations were performed on the healthier part of the population because of the low participation rate [25]. However, this issue was addressed by another analysis, in which we compared a sample of participants that had undergone spirometry with the entire sample of the HAPIEE Project; this other analysis showed that no difference in the two groups was observed on the prevalence of CVD risk factors (not discussed in the 'Results' section). Moreover, our previous findings revealed that the HAPIEE respondents did not differ from the population of other large Polish towns for the classic risk factors [26]. Another limitation may be related to the SCORE risk assessment; in the analysis, we used an algorithm for high-risk countries, which was developed in 2003 [15]; however, in the Polish HAPIEE sample, this approach overestimated the 10-year mortality [27]. In 2015, a new system of CVD risk assessment in Poland called Pol-SCORE was developed and recalibrated [28], but we decided to use the first of these two, because the data on spirometry and CVD risk factors were collected between 2002 and 2005.

A less important limitation of our study, as related only to one covariate, could be that assessment of physical activity was based only on one self-reported question. In our study the percentage of participants who had the recommended level of physical activity was higher compared to findings of other Polish population-based studies, i.e. NATPOL and WOBASZ [29-31].

Despite the limitations, there are some advantages of the current study. We used the data collected from a large random sample of Kraków citizens and the variables of interest were measured using standardised methods. Pulmonary function was measured in accordance with the recommendations of European Respiratory Society [17], CVD risk factors were defined according to the European Guidelines on Cardiovascular Disease Prevention in Clinical Practice [16], and other measurements were collected using a standardised questionnaire.

In conclusion, impaired lung function was associated with higher CVD risk, which could be explained partly by adverse association between lung function and prevalence of obesity, hypertension, and diabetes.

Conflict of interest: Andrzej Pająk - honorarium from AMGEN and Sanofi not related to submitted work.

\section{References}

1. Ostrowski S, Barud W. Factors influencing lung function: are the predicted values for spirometry reliable enough? J Physiol Pharmacol. 2006; 57 Suppl 4: 263-271, indexed in Pubmed: 17072054.

2. Young RP, Hopkins R, Eaton TE. Forced expiratory volume in one second: not just a lung function test but a marker of premature death from all causes. Eur Respir J. 2007; 30(4): 616-622, doi: 10.1183/09031936.00021707, indexed in Pubmed: 17906084.

3. Arcari A, Magnacca S, Bracone F, et al. Moli-sani Investigators. Relation between pulmonary function and 10-year risk for cardiovascular disease among healthy men and women in Italy: the Moli-sani Project. Eur J Prev Cardiol. 2013; 20(5): 862-871, doi: 10.1177/2047487312447904, indexed in Pubmed: 22609891.

4. Shibata Y, Watanabe T, Osaka D, et al. Impairment of pulmonary function is an independent risk factor for atrial fibrillation: the Takahata study. Int J Med Sci. 2011; 8(7): 514-522, indexed in Pubmed: 21897765

5. Yeh F, Dixon AE, Best LG, et al. Obesity in adults is associated with reduced lung function in metabolic syndrome and diabetes: the Strong Heart Study. Diabetes Care. 2011; 34(10): 2306-2313, doi: 10.2337/dc11-0682, indexed in Pubmed: 21852681. 
6. Schnabel E, Nowak D, Brasche S, et al. Association between lung function, hypertension and blood pressure medication. Respir Med. 2011; 105(5): 727-733, doi: 10.1016/j.rmed.2010.12.023, indexed in Pubmed: 21276721.

7. Cirillo DJ, Agrawal Y, Cassano PA. Lipids and pulmonary function in the Third National Health and Nutrition Examination Survey. Am J Epidemiol. 2002; 155(9): 842-848, indexed in Pubmed: 11978588.

8. Harmsen L, Gottlieb V, Makowska Rasmussen L, et al. Asthma patients who smoke have signs of chronic airflow limitation before age 45. J Asthma. 2010; 47(4): 362-366, doi: 10.3109/02770901003692819, indexed in Pubmed: 20528587.

9. Rogliani P, Puxeddu E, Ciaprini C, et al. The time course of pulmonary function tests in COPD patients with different levels of blood eosinophils. Biomed Res Int. 2016; 2016: 4547953 , doi: 10.1155/2016/4547953, indexed in Pubmed: 27822474

10. Chen WL, Wang CC, Wu LW, et al. Relationship between lung function and metabolic syndrome. PLoS One. 2014; 9(10): e108989, doi: 10.1371/journal.pone.0108989, indexed in Pubmed: 25299452.

11. Oike T, Senjyu H, Higa N, et al. Detection of airflow limitation using the 11-Q and pulmonary function tests. Intern Med. 2013; 52(8): 887-893, indexed in Pubmed: 23583992.

12. Laurendi G, Donfrancesco C, Palmieri L, et al. Association of lifestyle and cardiovascular risk factors with lung function in a sample of the adult Italian population: a cross-sectional survey. Respiration. 2015; 89(1): 33-40, doi: 10.1159/000369035, indexed in Pubmed: 25592046.

13. Margretardottir OB, Thorleifsson SJ, Gudmundsson G, et al. Hypertension, systemic inflammation and body weight in relation to lung function impairment - an epidemiological study. COPD. 2009; 6(4): 250-255, indexed in Pubmed: 19811383.

14. Peasey A, Bobak M, Kubinova R, et al. Determinants of cardiovascular disease and other non-communicable diseases in Central and Eastern Europe: rationale and design of the HAPIEE study. BMC Public Health. 2006; 6: 255, doi: 10.1186/1471-2458-6-255, indexed in Pubmed: 17049075.

15. Conroy RM, Pyörälä K, Fitzgerald AP, et al. SCORE project group. Estimation of ten-year risk of fatal cardiovascular disease in Europe: the SCORE project. Eur Heart J. 2003; 24(11): 987-1003, indexed in Pubmed: 12788299.

16. Piepoli M, Hoes A, Agewall S, et al. [2016 European Guidelines on cardiovascular disease prevention in clinical practice]. Kardiol Pol. 2016; 74(9): 821-936, doi: 10.5603/kp.2016.0120.

17. Miller MR, Hankinson J, Brusasco V, et al. ATS/ERS Task Force. Standardisation of spirometry. Eur Respir J. 2005; 26(2): 319-338, doi: 10.1183/09031936.05.00034805, indexed in Pubmed: 16055882 .

18. Nizankowska-Mogilnicka E, Mejza F, Buist AS, et al. Prevalence of COPD and tobacco smoking in Malopolska region - results from the BOLD study in Poland. Pol Arch Med Wewn. 2007; 117(9): 402-410, indexed in Pubmed: 18062562.

19. van Huisstede A, Cabezas MC, Birnie E, et al. Systemic inflammation and lung function impairment in morbidly obese subjects with the metabolic syndrome. J Obes. 2013; 2013: 131349, doi: 10.1155/2013/131349, indexed in Pubmed: 23509614.
20. Sin DD, Man SF. Why are patients with chronic obstructive pulmonary disease at increased risk of cardiovascular diseases? The potential role of systemic inflammation in chronic obstructive pulmonary disease. Circulation. 2003; 107(11): 1514-1519, indexed in Pubmed: 12654609.

21. Litonjua AA, Lazarus R, Sparrow D, et al. Lung function in type 2 diabetes: the Normative Aging Study. Respir Med. 2005; 99(12): 1583-1590, doi: 10.1016/j.rmed.2005.03.023, indexed in Pubmed: 16291079.

22. Mannino DM, Thorn D, Swensen A, et al. Prevalence and outcomes of diabetes, hypertension and cardiovascular disease in COPD. Eur Respir J. 2008; 32(4): 962-969, doi: 10.1183/09031936.00012408, indexed in Pubmed: 18579551.

23. Zureik M, Benetos A, Neukirch C, et al. Reduced pulmonary function is associated with central arterial stiffness in men. Am JRespir Crit Care Med. 2001; 164(12): 2181-2185, doi: 10.1164/ajrccm.164.12.2107137, indexed in Pubmed: 11751184.

24. Cuttica MJ, Colangelo LA, Shah SJ, et al. Loss of Lung Health from Young Adulthood and Cardiac Phenotypes in Middle Age. Am J Respir Crit Care Med. 2015; 192(1): 76-85, doi: 10.1164/rccm.201501-01160C, indexed in Pubmed: 25876160.

25. Topor-Madry R. Bobak M, Pajak A. 5-year mortality in respondents and nonrespondent for the cohort study of 20000 randomly selected middle aged men and women. The HAPIEE Project. Eur J Prev Cardiol. 2012; 19(Suppl 1): S71.

26. Doryńska A, Polak M, Kozela M, et al. Cardiovascular disease (CVD) risk factors in Kraków and in the whole Poland adult population. Results from the WOBASZ study and Polish arm of the HAPIEE project. Przegl Epidemiol. 2015; 69(1): 79-86, 175, indexed in Pubmed: 25862452.

27. Vikhireva O, Pajak A, Broda G, et al. SCORE performance in Central and Eastern Europe and former Soviet Union: MONICA and HAPIEE results. Eur Heart J. 2014; 35(9): 571-577, doi: 10.1093/eurhearti/eht189, indexed in Pubmed: 23786858.

28. Zdrojewski T, Jankowski P, Bandosz P, et al. [A new version of cardiovascular risk assessment system and risk charts calibrated for Polish population]. Kardiol Pol. 2015; 73(10): 958-961, doi: 10.5603/KP.2015.0182, indexed in Pubmed: 26521843.

29. Drygas W, Sakłak W, Kwaśniewska M, et al. Epidemiology of physical activity in adult Polish population in the second decade of the 21st century. Results of the NATPOL 2011 study. Int J Occup Med Environ Health. 2013; 26(6): 846-855, doi: 10.2478/s13382-013-0160-9, indexed in Pubmed: 24464564.

30. Drygas W, Kwaśniewska M, Kaleta D, et al. Epidemiology of physical inactivity in Poland: prevalence and determinants in a former communist country in socioeconomic transition. Public Health. 2009; 123(9): 592-597, doi: 10.1016/j.puhe.2009.08.004, indexed in Pubmed: 19740497.

31. Kwaśniewska M, Pikala M, Bielecki W, et al. Ten-Year Changes in the Prevalence and Socio-Demographic Determinants of Physical Activity among Polish Adults Aged 20 to 74 Years. Results of the National Multicenter Health Surveys WOBASZ (2003-2005) and WOBASZ II (2013-2014). PLoS One. 2016; 11(6): e0156766, doi: 10.1371/journal.pone.0156766, indexed in Pubmed: 27272130.

Cite this article as: Polak M, Doryńska A, Szafraniec K, et al. Cardiovascular risk assessment, cardiovascular disease risk factors, and lung function parameters. Kardiol Pol. 2018; 76(7): 1055-1063, doi: 10.5603/KP.a2018.0055 